\title{
Educational Practice of the Public Science and Technology Thesis Writing Course in Comprehensive University
}

\author{
Dayong Huo \\ Kashgar University, Kashgar 844006, China \\ hnnyhdy@163.com
}

\begin{abstract}
Keywords: Science and technology thesis writing; Teaching methods; Kashgar University; Large-class lectures; Literature retrieval and utilization; Reading practice
\end{abstract}

\begin{abstract}
Taking example for Kashgar University, this paper discusses the theory-practice integrated teaching methods of the public Science and Technology Thesis Writing course, which is set up for the undergraduate students from various professions. While analyzing the existing five problems in the academic thesis writing of Comprehensive University undergraduate students(such as the topic is too broad or too narrow, the digression or deviation of the main topic, bad at gathering related materials, related materials cannot be reasonably selected and ineffective reading and analyzing), related solutions are summarized based on the teaching examples. Correspondingly five science and technology thesis writing strategies for undergraduate students are proposed: reading practice, literature retrieval and utilization training, sample analysis of science and technology thesis, writing practice on specific topics and revise and contribution practice. In addition, this paper indicates the conflict between the large-class lectures and discussion-based lectures designed for individual students and students of different professions, and the teaching methods of large-class lectures that combine class discussion with group discussion.
\end{abstract}

\section{Introduction}

Research has shown that, the cultivation of science and technology thesis writing skills is of great significance in improving the knowledge structure, perfecting the thinking pattern and enhancing thesis-writing skills of undergraduate students. [1] At present, related courses as the Science and Technology Thesis Writing are opened in many universities, and to some extent, it helps in improving thesis-writing skills. Nonetheless, after the evaluation of the topic selection, the experiments implementation, and the form and content of the finished graduation thesis, one can see that the essence of the graduation design was not presented fully and efficiently due to the existent deficiency in the graduation thesis's guidance and instruction, which determines the quality of the graduation thesis [2][3]. Article 4 to 9 emphasized the technical writing skills as the essential quality that every undergraduate student must have mastered.

\section{The Curriculum Status of the Public Science and Technology Thesis Writing Course in Kashgar University}

The Curriculum of the Public. Science and Technology Thesis Writing course. Kashgar University is an application-oriented technical university of multi-ethnic groups, multi-disciplinary integration and multi-form. The institution now has 48 undergraduate programs, having nine departments of disciplines as pedagogy, literature, history, science, law, engineering, management science, economics and art. Aiming at improving students' comprehensive character, Kashgar University has a policy that in the cultivating program for higher specialized students, 8 credits are offered in the public elective courses, including Gym class, Literature and Art, liberal and science curriculum. The courses are for all postgraduates and undergraduate students in their second year or higher.

According to the five restrictive problems existing in the Graduation Thesis (less innovation, inappropriate topic selection, low thesis quality, improper form and plagiarism result from nonstandard references cite), and the compilation requirement for undergraduate innovation and 
entrepreneurship training projects' declaration, Kashgar University has begun to offer public Science and Technology Thesis Writing course and related public Literature Retrieval and Reading Practice course since 2015. So far, this course has been set for two years. On the first session, 72 students chose this course, 6 lectures were organized with a total of 1200 people's joining. On the second session, 100 students chose this course. On the third session, 100 students chose this course, 5 lectures were organized with a total of 1100 people's joining. On the fourth session, 100 students chose this course.

The Faculty of the Science and Technology Thesis Writing Course. At present, in Kashgar University, the public Science and Technology Thesis Writing course is set up by a full-time professor of Electrical engineering and the automation specialty who has also a qualification of senior engineer and professor. With the work experience as an education researcher and university journal editor, this professor has an editor qualification certificate issued by the General Administration of Press and Publication of the Peoples' Republic of China. Not only written and published 40 more literary works such as proses and novels , 100 more professional science and technology thesis, and 20 more educational research and reform articles, this professor also has host more than ten research projects. During the educational practice, this professor can instruct thesis writing of various kinds of literary styles of students majoring in different specialties to guarantee the discussion-based class process.

Teaching Effect. Study showed that, students in Kashgar University who chose the public Science and Technology Thesis Writing course and related public Literature Retrieval and Reading Practice course has made a remarkable progress in the quality of Graduation Thesis, innovation and entrepreneurship training projects' declaration and comprehensive works. Among these students, the evaluations of graduation theses are good and above, simultaneously, the percentage of all the students whose graduation thesis evaluation is good and above is $65 \%$. Besides, students selected this course all take an active part in the innovation and entrepreneurship training projects and $80 \%$ of them have obtained the approval of the projects, whereas the percentage of all the students is merely $50 \%$.

\section{The Existing Five Problems in the Academic Thesis Writing of Comprehensive University Undergraduate Students}

While analyzing the curriculum of the public Science and Technology Thesis Writing course in Kashgar University, five problems exists in the academic thesis writing of Comprehensive University undergraduate students.

The Topic Is too Broad or too Narrow. The research direction stems from the topic selection, which determines the scope of the paper or the research report. Appropriate thesis topic selection is conductive to the accomplishment of a high-level yet valuable graduation thesis, whereas an inappropriate thesis topic selection is incapable of undertaking intensive research and thesis writing which result in graduation thesis writing difficulties. There are several problems lie in the topic selection of graduation thesis: the topic is too broad, the topic is old-fashioned and lack of innovation, the topic is too concentrated and lack of challenging.

Example 1: A student majors in law choose the Study of Chinese Law as the graduation thesis topic. As for an undergraduate student, this topic is way too much broad. It is beyond his or her ability to conduct research or study either for the thesis topic or for the interest-oriented research.

Example 2: The students of science in normal universities choose the Newton's Second Law as the topic of instructional design. The topic is too narrow and the limitation of this topic is obvious. Hence what will be covered under this topic is narrow, the size of the thesis is small and the learning outcomes cannot be fully demonstrated.

The Digression or Deviation of the Main Topic. One problem is the digression from one's own point, and lack of enough pertinence and logic when writing. Another problem is the inconformity between the discourses and the related supportive materials with the main ideas that one intends to express.

Example 3: Writing an article titled as the Naan of Kashgar, if one merely focuses on how it is 
cooked, and then the main idea cannot be fully demonstrated.

Example 4: Writing an article titled as the Naan of Kashgar, if one merely discusses the food of Xin Jiang, then the article must have strayed from the point.

Bad at Gathering Related Materials. Some students have a great idea about the thesis writing, however, they cannot filter supportive materials. Therefore, the expression of their thesis augments is not clear, and the grounds of the arguments are not sufficient.

Related Materials cannot Be Reasonably Selected. While collecting materials, outlining and writing graduation thesis, the correct way that "analysis first, summary then, conclusion at last and see the related materials as references" was not of good use, as a contrast, some students only "copy materials on the basis of the outline they set before ". Consequently, students are struggling under a mountain of plagiarizing and fabricating. ${ }^{[3]}$

Reading and Analyzing Ineffectively. Facing the numerous related materials, some students cannot find out the main idea and supportive materials related to the subject. As a result, their theses were loaded with superfluous materials and the content of their argument were weak.

\section{Five Science and Technology Thesis Writing Strategies for Undergraduate Students}

To solve the above problems, during the establishment of the course of the Science and Technology Thesis Writing, Kashgar University made an attempt to five relevant strategies on the basis of the standard thesis format and normalized teaching.

Literature Retrieval and Utilization Training. Based on a specific topic, organize students to fresh their minds and clarify their thoughts, learn to effectively retrieve relevant materials.

When having a writing class, take the topic the Naan of Kashgar for an instance, we can make a road map to guide students as they write: the food of Kashgar, Naan, the essential part that Naan takes in Kashgar' food, the nutrient value of Naan, the way the Naan being prepared, the differences of Naan between Kashgar and other region, the development of the Naan, and the prospect of Kashgar' Naan.

From the writing thoughts given above, guide students to search the related literature. Select the applicable Search Term: food, Kashgar' food, Naan, Kashgar' Naan, the production of Naan, the nutrient value of Naan, the cooked wheaten food, baked food, climate and eating habits, and the trophic structure.

In retrieval, professor should train students in narrowing down the range of retrieval, applying the paper-book retrieval methods and the convenient retrieval of e-resources. Finally, students can find out their own interested topics, and organize the supportive materials of science and technology thesis.

Reading Practice. The materials we retrieved from the Internet and library are confusing and numerous. How to seek out the related and useful materials? The most efficient way is reading. When carrying on technical reading practice for students, we focus on the fast retrieval for the needed materials.

First and foremost, read the titles. We can tell whether an article or a book is identical with our targets or not by the titles. Secondly, check out the key words, which means that professors must make sure that students are equipped to the ability to set the key words. For example, writing an article titled as the Naan of Kashgar, we can set the key words as Kashgar, Naan, food, folk culture and catering culture. Finally, view the abstracts of the articles, and check out the compatibility of themes.

By the method of class reading and discussion, lead students to retrieve useful information from a specific article. For instance, pick up an article with more than a thousand characters but without a title for students, then after reading, have a test that requires adding title and marking keywords for students. Through repeated practice and discussion, achieve the goal of retrieve appropriate materials.

Sample Analysis of Science and Technology Thesis. Although most universities publish the specification for graduation thesis, the finished theses also have lots of problems: nonstandard thesis and abstract format, wrong dimension units, inappropriate uses of charts, graphs, numbers, language, 
characters, references, keywords and signature.

During the class, the professor introduces the whole process of thesis writing from topic research to thesis publication to standardize the thesis format. At the same time, while conducting sample analysis of science and technology thesis, class discussion is also put into use. Professors compile series of materials with typical mistakes for students to edit and revise so that they can master the standard formats of thesis writing and the argument structure as well.

Writing Practice on Specific Topics. The essence of science and technology thesis writing training is writing. While having a writing class, students are required to choose a research direction or an interested subject according to their interests and professions. In addition, based on the characteristics of multiple disciplines in Kashgar University, select a public research subject suitable for all the students. In 2015, the public subject we selected is the Naan of Kashgar, correspondingly the "Four Together" Principle to minority and Han students in 2016. In the teaching process, professors carry out the reading practice, retrieving practice and writing practice positively on the foundation of public subject. Based on their own subjects, students can take some pertinent training under the individual guidance by professors. The class discussion is universal for both the writing practices.

During the class, six class writing practices are required, three practices for the public subject and three practices for personal subject respectively. The writing practice includes outline practice, format and structure practice and composition practice.

At the end of each term, an innovation and entrepreneurship training projects' declaration training will be performed as a basic training for the actual project application.

Revise and Contribution Practice. Beside the four steps above, the edit, review, revise and contribution practices are also indispensable. In this section, the revise and contribution practice is completed by the panel discussion. In the whole teaching course, professors make sure that they write and contribute 2 to 3 science and technology articles, and provide real-time process information to help students to receive the general details for theses publication.

\section{The Resolution of the Conflict between "the Large-Class Lectures" and "Discussion-based Lectures"}

Currently, large-class lectures accounts for a large part. In Kashgar University, the upper limit number of students who can choose the public science and technology thesis writing course is 100 .

Conflict exists between "the large-class lectures" and "discussion-based lectures". The large-class lectures system of public courses indicates that students who attend the class differ in professions, which makes it difficult to apply the discussion-based lectures. To solve these problems, following policies were adopted.

Divide Students into Groups in Large Classes. Professor groups 100 students into 8 or 10 learning-groups by interests. On the one hand, the validity of class discussion can be guaranteed; on the other hand, the teaching effect can be more effective through the impact of peer effect.

The Duel Track of Class Sample Activities. As is depicted, professors select a public research subject, at the same time, students are required to choose a research direction or an interested subject according to their interests and professions to do targeted training under the individual guidance of professors. The class discussion is universal for both the writing practices.

Task-driven Method. Determined assignments are assigned in each writing class, and the tasks of the next class are clear. Students think with relevant questions inn mind, and develop new knowledge growth points concentrating on these questions. As for the assignments, they are universal and distinctive as well.

\section{Conclusion}

At present, many universities and colleges have set up the public science and technology thesis writing course. Due to the different professional backgrounds of course teachers and the comprehension difference of instructional contents, the teaching results differ largely. [3] In the 
public science and technology thesis writing course, Kashgar University implements the training methods that combine theory with practice. Meanwhile, to seek out resolutions of the conflict between "the large-class lectures" and "discussion-based lectures", following the progressive training methods of literature retrieval and utilization training, reading practice, sample analysis of science and technology thesis, writing practice on specific topics and the revise and contribution practice, Kashgar University divides students into groups in large classes, adopts the duel track of class sample activities and task-driven method. These beneficial attempts should be further modified and strengthened in the future educational practice.

\section{Acknowledgements}

This research was financially supported by the 2015 Teaching Reform Research Planning Project of Kashgar University (KJAZ1503)

\section{References}

[1] L.L. Gao, M. Zhang and Z.Q. Ge: The Cultivation of Academic Thesis Writing Ability of University Student Based on the Project-driven [J] (In Chinese). Digital Lifestyle Devices, 2014,(5):42-44.

[2] X. Gao and B.J Zhang: The Positive Influence in the Graduation Thesis Quality of the Reform of The science and technology thesis writing Course[J](In Chinese). Education Teaching Forum, 2016, (9):92-93.

[3] J. Shang: University Journal in the Discipline Construction of Sci-tech Essay Writing [J]. Journal of Guangdong Ocean University (In Chinese). Vol. 33 (2013) No.5, pp98-100.

[4] J.J. Yang, L.P. Zou and D.X. Xia: Thinking of the Improvement of the Graduation Thesis Quality of Undergraduate Students[J](In Chinese). Journal of the Air Force Institution.

[5] National Undergraduate Innovation and Entrepreneurship Training Program expert working group. National college students' innovative entrepreneurial training program manual work [D]

(In Chinese ) .Ministry of education of the People's Republic of China.2012.11

[6] Undergraduate Innovation and Entrepreneurship Training Program and implementation plan of the xinjiang uygur autonomous region [M] (In Chinese). The education department of xinjiang uygur autonomous region. 2015.03

[7] B. Yu and X.B. Yan: Exploration and practice on project management of "Undergraduate Innovation and Entrepreneurship Training Program" [J] (In Chinese). Experimental Technology and Management .Vol.32 (2015) No.9, pp30-33

[8] Y.D. Liu, L.Y. Ren and L.Y. Feng: Understanding of the National Undergraduate Innovation and Entrepreneurship Training Program [J] (In Chinese). Journal of Inner Mongolia Normal University (Educational Science).Vol.27 (2014) No.1, pp7-10

[9] J.W. Zhang, Z. Zhang, X.M. Chang, R. Zhang and Y.Q. Cheng: Exploration and Practice of the Effectiveness of Process Management in Local College Students' Innovative Training Program [J] (In Chinese). Research in Higher Education of Engineering. Vol.32 (2014) No.5, pp135-138

[10]Z.J. Wu, C.L. Huang: The Concept and Cultivation of Applied Talents [J] (In Chinese). Research in Higher Education of Engineering. Vol.32 (2014) No.2, pp.66-70. 